\title{
EDUCATION
}

\section{Some Critical Issues in Special Needs Education as they Relate to Visual Impairment in Nigeria}

\author{
Charity A. Andzayi and Sylvester M. Yakwal \\ University of Jos, Jos - Nigeria
}

\begin{abstract}
The study examines five critical issues in special education as they relate to visual impairment vis a vis mercy killing (euthanasia), gender, seclusion, castration and genetic engineering. Literature in the five stated issues was reviewed to provide an insight into these areas with particular reference to visual impairment. A sampled group of graduates some of who are post graduate students in special education (visual handicaps) numbering 30 participated in the study. Their opinions on the five critical issues were gathered using a ten-item researcher constructed questionnaire and analysed by simple percentage. One of the major findings was that respondents were generally not too familiar with four of the five issues in special education as they relate to visual impairment and therefore are not contending issues. However, one of the critical issues (seclusion) was deemed to be a relevant issue in this respect. It was therefore suggested that interventions should be carried out through public education and increased advocacy as well as inclusion of such topics in the courses taught during the undergraduate and postgraduate programmes in special education.
\end{abstract}

\section{Introduction}

Helen Keller (1880-1968), described by Ozoji (2003) as the veteran deafblind genius during the peak of her life, was said to have made a statement on attitudes that has now become legendary. She reportedly said that it is "not blindness but the attitude of the society towards blindness that is the greatest burden to bear". Since that time, the word 'attitude' has featured frequently in special education literature. 
According to Ozoji (2003) attitude is a human expression that is made up of three interrelated components: beliefs, feelings and behaviour. In this regard, attitudes manifest in an individual when such an individual forms an opinion (belief) that is an inherent feeling tone about the attitude object and subsequently behaves towards the attitude object either positively or negatively. It has been generally acknowledged that the attitude of society towards persons with disabilities has been negative. This is largely because, as pointed out by Ozoji, attitudes in general begin from beliefs which represent what one believes or accepts as the truth or otherwise about an object, in this case a person with visual impairment. Abang (2005) reports that before the advent of Christianity, babies born with impairments or those who became impaired had little or no chance of survival because they were either abandoned in the forest to die or killed. According to her, in some parts of Africa, severely retarded children or those born with severe physical defects such as macrocephalus or hydrocephalus were not considered to be human beings, but animals in human form. Abang claimed that people believed that if they were left to live, they would prevent normal children from being born in those families or in the neighbourhood and therefore should be killed. She states that:

$\ldots$ if the people of that tribe were forest oriented, they would say that the handicapped child was a lion, a tiger or even a snake. If they are people who lived by the sea or river, they would say that the disabled child came from the sea or river as the case may be to be born. The child was believed to be a crocodile, a fish or a crab. The end of these children was death (Abang, 2005: 27).

It is against this background that the study on critical issues in special education as they relate to visual impairment has been initiated. As part of the study, attempts have been made to review relevant literature on the concept of visual impairment and the five identified critical issues - mercy killing (euthanasia), gender, seclusion, castration and genetic engineering.

\section{Visual impairments: a conceptual framework}

According to Kimbrough (1976), vision is a person's primary method of gaining information about the environment and also acts as a countercheck for all other sensory information. Lack of vision therefore serves as a serious impediment to an individual being able to function properly.

Sykes and Ozoji (1992) described visual impairment as the reduced function of the eye that is often measured by specific visual tests. Abang (2005) states that visual impairment which results from visual problems could be remedied either by surgical operation or by optical corrections. She identified the visually impaired to include the partially sighted (now 
referred to as low vision) and those who are totally blind (severe loss of visual acuity).

There is no doubt that visual impairment results in the reduced ability of an individual in tasks such as reading, mobility and independent living skills. According to Milaham (2000), people of all age groups around the world need to be mobile in order to carry out their daily life activities safely and satisfactorily. Lack of sight or inadequate vision is no doubt a great impediment to successful living.

The visually impaired, according to Ozoji (2003) are children in whom the sense of vision is defective leading to ability to see a little or become totally blind. Such children are visually disabled when they cannot perform tasks requiring vision such as reading print. On the other hand, they are visually handicapped when they encounter difficulties that prevent them from total integration into the society.

Arising from common beliefs and attitudes towards persons with disabilities, Ozoji (2003) identified over twenty of such beliefs that range from the mundane to the ridiculous. These include the following:

- Impairment occurs when the person breaks taboos in the community.

- Impairment results from the evils committed by parents.

- Impairment is a sign of curse on a family.

- Disabled persons come from the sea.

- Disabled persons are asexual.

- Disabled body has a disabled mind.

- Smallpox and measles are divine visitations demanding people's eyes.

- Disabled people are wards of the society and so should be protected.

- Blindness is associated with some gifts.

- Impairment is contagious.

- Impairment is a bad omen

- Impairment is a punishment for the adulterous mother.

- It is God's will that disabled persons should beg.

- Impairment is a work of God displayed.

- Disabled persons are good native doctors.

- Blind people move around through the assistance of the spirits.

- $\quad$ Eating and drinking with the blind will make one blind as well.

- Looking at a woman's vagina while having sex is a cause of blindness in children.

- Disabled persons are feared as witches.

- They are believed to see the mind of others. 
- They are neglected because they became disabled due to the fault of parents or forefathers.

- Belief in retributive justice or the law of Karma at work.

- They are second rated individuals.

- The blind have good memory.

- They are regarded as source of shame to the family that is why some of them are locked up when visitors are around.

- They are unusually hostile.

The expressions above portray the negative feelings or beliefs that people have or hold towards persons with disabilities. Going by what Orji (1986) as quoted by Abang (2005) says, the main causes of visual loss in Nigeria include infection, malnutrition and ocular trauma. One could also add poverty, wars and conflict situations including religious, communal and sectoral violence.

In view of the many beliefs held in relation to visual impairment in particular and disabilities in general, what issues should be considered in special needs education with particular reference to visual impairments?

\section{Critical issues as they relate to visual impairments}

According to the Oxford Advanced Learner's Dictionary of current English (Hornby, 2001) anything critical is something that is extremely important because a future situation will be affected by it while an issue is an important topic that people are discussing or arguing about. If that is the case, then critical issues could be equated with serious, uncertain and possibly dangerous thinking about anything of interest, in this case special needs education with particular emphasis on visual impairment.

Similarly, critical issues in special needs education could be seen as alternative choices made about some of its aspects like obtained in the principles of opportunity cost in economics where an individual have to make choices as a result of prevailing circumstance at his or her disposal. The critical issues in special education examined in this study as relates to visual impairment in Nigeria include mercy killing, gender, seclusion, castration, and genetic engineering.

\section{Mercy killing}

Mercy killing has been defined as the killing by one person of another who has an incurable illness or injury in its final and most painful stages. When mercy killing occurs with the consent of the patient, it is called voluntary but when performed upon an incapacitated person or against a person's wishes, it is called involuntary. (www.setnlegalservices.org/glossary.htm). Euthanasia on the other hand, is the act of killing a person or animal in a 
painless or minimally painful way, for merciful reasons, usually to end their suffering. (en.wikipedia.org/wiki/mercykilling)

There are three types of euthanasia: causing the death of a person through a direct action in response to a request from that person; physician assisted suicide which involve a physician supplying information and or the means of committing suicide to a person so that such a person can terminate his or her own life and involuntary euthanasia which describes the killing of a person who has explicitly requested aid in dying.

People have many different reasons for wanting to end their life by committing suicide. These include being severely depressed over a long interval, living in excessive chronic pain, having a terminal illness and having a serious disorder or disease that has adversely affected their quality of life to the point where they no longer wish to continue living. Other reasons may be having been diagnosed with a progressively degenerative illness, having lost independence and therefore must be cared for continually, realizing that they will be dying in the near future and wanting to have total control of the process and being concerned about the future.

According to Hauser (n.d), many people feel that euthanasia and assisted suicide are needed because people who are connected to machines to stay alive do not have a high quality of life and so should have the right to not be among the living anymore if they so choose. In relation to special needs persons, the argument may be that one may have severe disability that could prompt such an individual to choose euthanasia as a way out. As far as its known now, there is little or no literature to support this assumption. However, such a situation cannot be totally ruled out in the light of reports by Abang (2005) on the treatment meted out to persons with severe disabilities in the early times because of cultural beliefs and attitudes towards persons with disabilities. This could be a subject of future research in the area of special needs education.

\section{Gender}

The term 'gender' has assumed a very important and indeed strategic connotation in general discussions on development. While some people are known to view gender and sex as synonymous, it is clear that the two words, even though closely related, mean different things. While sex refers to the biologically determined characteristics or functions of males or females, gender refers to those functions society ascribes or assigns to males or females. While defining the concept of gender, Ityavar (2001) states that it is the roles that men and women play and the relation that arise out of these roles. According to him, they are socially constructed and not physically determined.

Omatseye (2004) on the other hand, sees gender as the sense of being male or female with a line of demarcation running between sex and gender that should not be mixed-up. Because physical characteristics associated 
with sex lead to gender differences, society expects males and females to behave differently and to assume different roles in order to conform to expectations.

What about gender parity, gender equity and gender equality? Gender parity refers to quality of opportunities for access for both boys and girls. Gender equity refers to the process (or educational experiences) to which learners are exposed to as well as to the outcomes (or extent to which learning has taken place). Gender equality, on the other hand, refers to bringing the two together interactively to provide access for both boys and girls including those with visual impairment.

The gender objectives of the draft gender policy for the University of Jos (Ityavar, 2005) for instance, is very instructive when considering gender issues in their global perspective. Ten objectives were stated in the draft gender policy and summarized below:-

- To ensure that male and female students and staff study, live and work in an environment of mutual respect, free from discrimination, harassment, hostility, intimidation, retaliation and humiliation thereby enhancing the dignity of both genders.

- To ensure the involvement of the minority gender at any point in time in University wide decision making processes as a way of carrying every body along and ensuring that decisions are collectively owned and defended.

- To ensure that all research, training and development activities in the University are gender sensitive and aimed at bringing out the best in both men and women.

- To ensure that the work place is gender friendly and supportive of men and women and their specific needs and roles.

- To ensure that gender mainstreaming and equity are both taken into consideration in long term university plans.

- To ensure that entry requirements into the University and related admission and recruitment processes for both students and staff reflect equity and are transparent and non discriminatory.

- To evolve a teaching and research culture that is gender sensitive and promotes non- discriminatory best practices and procedures in all aspects of the University including admission, employment and service delivery.

- To co-create a university community ( and the larger society) where both men and women are respected, valued and treated fairly, justly and equally.

- To enrich and strengthen diversity and encourage academic freedom and 
- To institutionalise the gender desegregation of all university data at the various points of generation and the periodic analysis of such data.

With such laudable objectives, it is hard to believe that the University of Jos, which is an institution that reflects the entire Nigerian society, would allow gender diversity to becloud its impact on gender as an option relating to the visually impaired generally.

\section{Seclusion}

Seclusion, which is a mode of restraint, is the placement of a client in a room alone and preventing him/her from leaving. This is a mode of behavioural intervention for disciplinary reasons due to inappropriate, out of control behaviour. According to the Wisconsin Department of Public Instruction (WDPI) (2005), seclusion or physical restraint is used to defuse a dangerous situation, protect the students and others from injury and regain a safe, controlled and productive learning environment. There are two major forms of seclusion. Involuntary seclusion occurs when a client is placed without his/her consent in a room and prevented from leaving or deliberately isolated from others and voluntary seclusion is when a client is physically restrained at his/her own request.

The WDPI provided the following guidelines for the use of seclusion:

- In a student's IEP if it is anticipated that such use will be necessary to address the student's behaviour.

- Teach the student what to expect when seclusion is going to be used.

- Set criteria for ending the seclusion period.

- Maintain constant adult supervision (e.g. visual contact) with the student while he/she is in the seclusion area.

- Develop written procedures so that the use of seclusion is consistent and planned in advance.

- Keep a log or incident report to record each use of seclusion.

- Create a safe, comfortable environment.

- Use seclusion only for the period of time necessary to accomplish its purpose and using no more force than is necessary.

Seclusion or physical restraint is expected to be used when a student's behaviour is an immediate threat to his/her safety and or the safety of others. It is also expected to be put in use only when there are no physical, medical, or other contraindications and if the staff using the method has been adequately trained in its safe application.

There is no doubt that some severely visually impaired children with probably chronic behaviour disorders (e.g. autism) may require this technique of behavioural intervention. Although this has not been 
established in the context of this study, there is need to keep an open mind on the application of seclusion and or physical restraint as a critical issue in relation to visual impairments.

\section{Castration}

According to Wikipedia, (file://A:Icastration Wikipedia, the free encyclopedia.htm) castration is any action, surgical, chemical or otherwise, by which a biological male loses use of the testes. This causes sterilization thereby preventing the male from reproducing or greatly reduces the production of certain hormones such as testosterone.

Wikipedia states that castration was frequently used in certain cultures such as in Europe, the Middle East, India, Africa or China for religious or social reasons. Some of the reasons that have been advanced for voluntary castration include the fact that it is used in modern societies for the control of libido, body modifications and in some cases of extreme sexual masochism for the purpose of sexual excitement. Involuntary castration, also appears in the history of warfare and was sometimes used by one side to torture or demoralize their enemies. The most noticeable and interesting aspect of castration is that it was also practiced to extinguish opposing male lineages and thus allow the victor to possess the defeated men's women. If this is the case, then it is possible that castration could be used to extinguish male lineages that are likely to sire children who may turn out to be severely disabled. This sheds some light on the possibility of using castration as an option in special needs education with particular reference to visual impairments

Badawi (1989) reports that in women, the genital mutilation technique almost always involves the removal of the clitoris and labia minora and to a lesser extent slashing the labia majora when it is bulky and protruding. According to him, in practice there is a wide range of technical variation of genital mutilations within the same practitioner across time, instrumentation used and with the socio-economic status, age, location, traditionalism and ethnicity of the child and her family.

Both castration and genital mutilation are subjects of debate and future research. Whatever the case may be, it shows clearly both topics could be considered in special needs education.

\section{Genetic engineering-}

Also known as genetic modification, genetic engineering is the deliberate, controlled manipulation of the genes in an organism with the intent of making that organism better in some way. Usually done independently of the natural reproductive process, human genetic engineering deals with the changing of a human being through the modification of the genetic structure. 
According to Wikipedia, (file://A:lHuman genetic engineering.htm) the changes are usually carried out by taking a trait from one species, whether animal or plant and transferring it to another species. To drastically change people's genomes genetic engineering could enable people to regrow limbs, the spine and the brain while disease could be prevented by detecting people that are genetically prone to certain hereditary diseases. However, while some scientists believe that introducing genetically modified genes may have an irreversible effect with consequences yet unknown, genetic engineering borderlines on many moral issues particularly involving religion which questions whether man has the right to manipulate the laws and course of nature. Turmusani (2005) claims that genetic research has made many positive contributions to human life such as overcoming deadly diseases and maximizing food production. Making reference to history, Turmusani posits that the implications of genetic research could contribute to the widespread rejection of anything less than complete and perfect. According to him, those with impairments might be considered as lesser human beings resulting in the creation of the notion of disability as a deviance and disabled people as a different species whose lives are not worth living. Turmusani argues that genetic technology and genetic research are not the solution to disabled people's problems but are contributing factors for creating disability when seeking perfection to minds and bodies.

The above argument makes one to speculate on the application of genetic engineering as a critical issue in special education as it relates to visual impairment. While one may get excited on the seeming possibilities associated with the usage of genetic engineering to cure or alleviate conditions that cause visual impairment, it is frightening to really assume that the visually impaired can offer themselves as genetic experimentation which is known to be irreversible, at least for now.

\section{The purpose of the study}

This study investigated the perception of graduates in special education with specialization in visual handicaps on the five critical issues: mercy killing (euthanasia), gender, seclusion, castration and genetic engineering.

\section{Research hypothesis $\left(\mathbf{H}_{\mathbf{0}}\right)$}

There will be no significant difference in the opinion of respondents on the five critical issues in special education as they relate to visual impairment. 


\section{Method and procedure}

\section{Design}

The survey research design was employed in this investigation. The opinion of graduates, some of who are postgraduate students in the Department of Special Education and Rehabilitation Sciences of the University of Jos, on the five critical issues in special education as they relate to visual impairment were gathered and analysed.

\section{Respondents}

A total of 30 respondents, (6 were postgraduate students) participated in the study. All the respondents were those that could be located within and outside the University of Jos at the time of the study. They had a mean age of 39 years and a mean work experience of 12 years and 20 respondents, representing $66.67 \%$, were males while $10(33.33 \%)$ were females. All this indicate that the participants in this study could be regarded as mature and highly responsible individuals whose opinions could be relied upon.

\section{Instrument}

The only research tool used for data collection was a researcher constructed anonymous two-part questionnaire consisting of 10 items. Part one included pertinent personal data while part two sought their opinion on five issues in special education as they relate to visual impairment. This instrument for data collection was validated by two lecturers in the Department of Special Education and Rehabilitation Sciences, University of Jos and was used to elicit information from the respondents.

\section{Results and discussion}

The results of the study and data providing justification for the $\mathrm{H}_{\mathrm{o}}$ hypothesis formulated is shown in the table below. The table indicates that the majority of respondents $83.33 \%$ and $66.67 \%$ agreed that seclusion (items 5 and 6) is a familiar option used in relation to visual impairment.

On gender as an issue in special education that relates to visual impairment, the opinion of respondents was equally divided on whether it is a familiar terminology but majority of the respondents $25(83.33 \%)$ disagreed that visual impairment is a product of gender (item 4). On mercy killing (euthanasia), castration and genetic engineering as critical issues in special education with particular relations to visual impairment, majority of respondents (items $1,2,7,8,9,10$ ) disagreed that they were either familiar with these terms or that they have any relations with visual impairments. This infers that although these terminologies and practices exist, there is no threat to such practices extending to the Nigerian situation. 
Percentage of responses showing the opinion of respondents on the five critical issues in special education as they relate to visual impairment

\begin{tabular}{|c|c|c|c|c|c|c|}
\hline Item & Statement & \multicolumn{2}{|c|}{ Agree } & \multicolumn{2}{|c|}{ Disagree } & Total \\
\hline & & No. & $\%$ & No. & $\%$ & $\%$ \\
\hline 1. & $\begin{array}{l}\text { Euthanasia (mercy killing) is a } \\
\text { familiar concept in special } \\
\text { education }\end{array}$ & 5 & 16.67 & 25 & 83.33 & 100 \\
\hline 2. & $\begin{array}{l}\text { Visual impairment has been } \\
\text { linked to mercy killing } \\
\text { (euthanasia) }\end{array}$ & 10 & 33.33 & 20 & 66.67 & 100 \\
\hline 3. & $\begin{array}{l}\text { Gender is a familiar issue in } \\
\text { relation to visual impairments }\end{array}$ & 15 & 50 & 15 & 50 & 100 \\
\hline 4. & $\begin{array}{l}\text { Visual impairment is a product } \\
\text { of gender }\end{array}$ & 5 & 16.67 & 25 & 83.33 & 100 \\
\hline 5. & $\begin{array}{l}\text { Seclusion is a familiar option } \\
\text { in relation to visual impairment }\end{array}$ & 25 & 83.33 & 5 & 16.67 & 100 \\
\hline 6. & $\begin{array}{l}\text { Seclusion is used as an option } \\
\text { in respect of visual impairment }\end{array}$ & 20 & 66.67 & 10 & 33.33 & 100 \\
\hline 7. & $\begin{array}{l}\text { Castration is closely linked } \\
\text { with visual impairment }\end{array}$ & 0 & 0 & 30 & 100 & 100 \\
\hline 8. & $\begin{array}{l}\text { Visual impairment provides a } \\
\text { basis for castration }\end{array}$ & 0 & 0 & 30 & 100 & 100 \\
\hline 9. & $\begin{array}{l}\text { Genetic engineering is a } \\
\text { familiar terminology in special } \\
\text { needs education }\end{array}$ & 10 & 33.33 & 20 & 66.67 & 100 \\
\hline 10. & $\begin{array}{l}\text { Genetic engineering is a } \\
\text { regular practice as an option to } \\
\text { visual impairment }\end{array}$ & 10 & 33.33 & 20 & 66.67 & 100 \\
\hline
\end{tabular}

\section{Recommendations/suggestions}

In view of the seeming lack of familiarity with most of the issues in special education as they relate to visual impairment considered in this study, there is need for urgent intervention in a number of areas. There is need for public education and advocacy on various issues including the five considered in this study.

Furthermore, it may be a good idea if the course content of the undergraduate and postgraduate teacher training programmes in special education (visual handicaps) are modified to include such sensitive issues at least to educate or provide basic information to students on similar issues.

\section{References}

Abang, T.B. (2005). The exceptional child: Handbook of special education. Jos: Fabs Educational Books

Badawi, M. (1989). Epidemiology of female sexual castration in Cairo, Egypt. Paper presented at the First International Symposium on circumcision, Anaheim, 
California March 1-2 Downloaded on Internet file://Afrirad8/e/top60. htm on 8.3.2005.

Hauser, B.(n.d). Mercy Killing file:/Nsurf 5\D\Mercykilling.htm on 8/4/2003

Hornby, A.S. (2001). Oxford Advanced Learner's Dictionary of Current English $\left(5^{\text {th }}\right.$ ed). Oxford University Press.

Ityavar, D.A (2001). Gender Sensitisation of Legislators in Nigeria: Participants Manual. Jos: Inter- Gender.

Ityavar, D.A. (2005). "Draft gender policy for the University of Jos". JosCarnegie Partnership

Kimbrough, J. A. (1976). Sensory training: A Curriculum Guide. Greater Pittsburgh: Guild for the Blind Professional series 2

Milaham, N. (2000). "Investigation Into The Specific Long Cane Techniques That Can be Taught to Nursery School Blind Children In Bauchi, Kano and Maiduguri". Journal of Research in Special Education 4(1), 92-98.

Ometseye, B.O. J. (2004). "The Gender Gap: Sexism in Kindergarten Classroom too?" The Jos Journal of Education. 7 (1), 71-73.

Ozoji , E. D (2003). Special Education for Beginner Professionals ( $2^{\text {nd }}$ ed) Jos: Deka Publications

Turmusani, M. (2005). "Genetic Technology and the UN Disability Convention." Disability World issue No. 26 December 2004- February 2005.

Wikipedia, the free encyclopedia: file://入: $\backslash$ Human Genetic Engineering.htm.

Wisconsin Department of Public Instruction (2005). "Guidelines for the appropriate use of seclusion and physical restraint in special education programmes." www.cde.state.co.us/dpedlaw/download/TimeOutGuidelines. pdf 